\title{
OS CAMARÕES FÓSSEIS DA FORMAÇÃO ROMUALDO NO ARARIPE PERNAMBUCANO: ASPECTOS TAXONÔMICOS E TAFONÔMICOS
}

\author{
Prado, L.A.C. ${ }^{1,}$; Calado, T.C.S. ${ }^{2}$ \& Barreto, A.M.F. ${ }^{1}$ \\ ${ }^{1}$ Universidade Federal de Pernambuco, Laboratório de Paleontologia-PALEOLAB, Recife, PE, Brasil. \\ ${ }^{2}$ Universidade Federal de Alagoas, Laboratório de Crustáceos Labmar/ICBS, Maceió, AL, Brasil.
}

*Autor correspondente: prado.lac@gmail.com

\begin{abstract}
A Formação Romualdo, Aptiano-Albiano da Bacia do Araripe, aflora nos estados de Pernambuco, Piauí e Ceará. Das quatro espécies de camarões descritas, Kellnerius jamacaruensis, Araripenaeus timidus, Sume marcosi e Paleomattea deliciosa, apenas essas duas últimas são relatadas para o Estado de Pernambuco. A fim de realizar um levantamento mais completo da fauna de decápodes no Araripe Pernambucano, foram realizadas coletas com controle estratigráfico nos municípios de Araripina, Ouricuri, Ipubi e Trindade. Em laboratório, foram analisados cerca de 300 elementos esqueletais, incluindo espécimes articulados e fragmentados. Como resultado foram identificados camarões sergestídeos da espécie $P$. deliciosa e um novo gênero e espécie em fase de identificação. Para obter uma melhor compreensão sobre a formação das associações fosseis ricas em camarões também foram realizadas análises tafonômicas que permitiram diferenciá-las em dois tipos. As associações tipo 1 ocorrem nas camadas de folhelho e são representadas por camarões articulados e soterrados in situ, logo após a morte, em condições de baixa energia. As associações tipo 2 ocorrem em camadas de arenito calcífero e também apresentam indivíduos articulados. Contudo, apresentam um alto índice de fragmentação, com restos tanto angulosos quanto arredondados o que pressupõe pelo menos em parte, remobilização ou transporte dos restos esqueléticos. Os resultados aumentam a diversidade e a distribuição geográfica de decápodes na Bacia do Araripe, e contribuem com as interpretações paleoambientais da Formação Romualdo.
\end{abstract}

Palavras-chave: crustáceos, decápodes, Sergestidae, Bacia do Araripe, Brasil. 